\title{
A prescription for cinematic lenses on child and adolescent health.
}

How does an infectious diseases paediatrician come to be sitting at Ingmar Bergman's desk on the island of Fårö, gazing out at the Baltic Sea? One could impose a cinematic narrative in media res. Pivotal moments, characters that weave through the entire piece, an occasional cameo. Did it begin with a long-haul flight watching "Beasts of the Southern Wild" and a thirst to talk to someone about questions it provoked? What is a suitable environment for a child to be brought up in? What is the role of the State and society in intervening with a family? How should this best be done? The camera pans left - one travelling companion asleep. The camera pans right - the other watching an episode of "Friends".

Those of us who work in child and adolescent health frequently encounter situations where the child's needs are influenced or compromised by their familial and societal environment. This is perhaps most keenly felt where there are safeguarding or mental health concerns and high stakes multi-disciplinary professionals' meetings are held. A revolving cast of doctors, nurses, therapists, teachers, social workers, and mental health professionals assemble and contribute their perspectives from their respective roles. This diverse forum of expertise, experience, and passion for maximising the wellbeing of children focuses acutely on the child at its centre and promptly dissolves as each actor returns to their silo and overwhelming burden of work.

Where is the space for us all to reflect on the broader themes that affect the children, young people, and families that we work with? To discuss issues of bullying, of violence, of war, of migration, of substance abuse, of gender, of disability, of inequality? In patient care the focus is rightly on a specific child in particular circumstances with unambiguous and actionable follow-up points. However, the weight of professional responsibility, the right to confidentiality, and time pressures inherently constrain the freedom to be curious, to think, to listen and to converse. Like society as a whole, those of us who work with children and young people often existed in fragmented groups who come together infrequently.

The communal act of watching a film offers us an opportunity to share a cultural experience, discuss its artistic and social themes, and stimulate thought in a manner complementary to our own professional and personal experiences. It can break boundaries between professions, between the arts and health sectors, and engage new audiences in thinking about child well-being. As Sandra Hebron, Head of Screen Arts at the National Film \& Television School and former director of the BFI (British Film Institute) London Film Festival, puts it "Film is an accessible artform and can be especially inclusive: we might not all have film studies degrees but we can all take something from watching a film. Cinema as a medium has the great potential to educate in the broadest sense as well as to entertain. It's also often referred to as an empathic medium, and as the late Anthony Minghella always used to say, it offers us the opportunity to see through someone else's eyes for a couple of hours. There's an immediacy to film that is very powerful - we are 
drawn in, swept up - all the phrases that people use when they talk about what they enjoy in cinema."

Certainly cinema as an art-form has generated a wealth of films that relate to childhood and adolescence, and this fascination has been studied extensively in the humanities. A notable contribution and a key catalyst in our own narrative arc is Mark Cousins' 2013 documentary "A Story of Children \& Film", and the accompanying BFI-supported "Cinema of Childhood" collection of films. Many directors have mined their own childhood experiences and displayed an interpretation of them to great dramatic effect for the viewer. As Ingmar Bergman said "My childhood has of course always been my main supplier, without my ever having bothered to find out where the deliveries were coming from."

Cinema can certainly provide us with rich material, but how can we provide a conducive environment to facilitate interdisciplinary discussions and reach audiences who otherwise might not relate their viewing experience to contemporary child health? Our events are open to all and follow a simple model of a great film shown in a beautiful place followed by conversation with interesting people. Panellists are usually drawn from the child mental health, film studies, and charitable sectors. Andrea Cunningham, Head of Learning at the V\&A Museum of Childhood, describes why this seems to work: "These events have allowed me to meet people who think and talk about childhood in totally different ways; from paediatricians and campaigners to film critics and historians. The films themselves are so diverse that they have prompted me to interrogate childhood differently. Much of the content is very powerful and it is good to be moved and provoked in this way at work; to be reminded of the wider significance of what you are engaging in. The panellists bring such diverse perspectives to the films some exploring the quality of the cinematic craft, some looking at the historical moment of its production and some talking about the real social, physical and psychological impacts for children across time. It gives the discussions a real gritty power which is not always present in purely academic presentations."

A good example of this is the recent exhibition "Bedrooms of London" at The Foundling Museum in London. Each photograph captured the bedroom of a child living below the poverty line in contemporary London, with the exhibition housed within a museum to the Foundling Hospital, the UK's first children's charity and first public art gallery, established in 1739 by the philanthropist Thomas Coram to care for babies at risk of abandonment. A season of film screenings curated to complement the exhibition highlighted challenging childhood environments. The bright palette of Sean Baker's "The Florida Project" and six-year-old Moonee's boundless energy can't hide the bitter truths underlying their existence in unstable housing in the shadow of Disneyland. Katie's adolescence on a council estate in Essex is harsh, with affection a scarce resource that is accompanied by hidden agendas in Andrea Arnold's "Fish Tank". By contrast, 13 year old teenage girl, Tom's childhood might represent the envy of those of us cooped up in crowded cities as she has a powerful bond to the natural world in her nomadic life in the wild parks of Oregon. Nevertheless, in Debra Granik's “Leave No Trace” the paucity of social interaction beyond that provided by her caring father limit her in other ways. Stephen Baker, a member of the Association of Child Psychotherapists and an NHS Child and Mental Health Services (CAMHS) practitioner, reflects "Three 
different families and cultures, on the edges of society, interestingly each with a single parent. The child's relationship with the parent is shown in painful close-up with a juxtaposition of love and, almost unwitting, neglect. But we come to see that the child is not a passive victim and then find pleasure in seeing an internal life force asserting itself, sometimes against the parent, and sometimes wider society. As a viewer there is enjoyment in seeing the child acquiring an almost precocious understanding of the adult world but then for Katie and Moonee a painful realisation of what they cannot know. In contrast, Tom develops a realisation of her father's fragile mental health and needs to break free. The cinematic aesthetic can be double edged, on occasion it can portray pain, almost unbearable to watch, and yet scenes beautifully shot can disguise the truth. Thus a film buff might view a character's journey as a dramatic odyssey, whilst health professionals might view it as a portrayal of abuse."

Of course there are existential critiques of the approach. In an era of echo chambers and preaching to the converted, it would be naïve to think that challenging independent films shown in a museum with a panel discussion afterwards would entice in audiences that are not already receptive to what they will see and hear. And this is, perhaps, where the IKEA-model of choosing from ready-made materials but adapting to the specific needs and space is critical. For instance, to engage more directly with children and young people and involve them fundamentally in these conversations, the choice of film, the setting in which it is shown, and the nature of the event are all key permutations that need to be carefully considered.

The contemporary health system's emphasis on measurable outcomes, audits and governance does not allow much space for intangible experiences such as those described here. Nor is Ingmar Bergman's bleak and nihilistic perspective a generous light with which to view the value of one's own activities. But cherrypicking two aspects of his approach to cinema could serve as inspiration to the endeavour. He cites an "unbounded, never satisfied, continuously renewed, unbearable curiosity" as the driving force behind his artistic urge in his 1965 essay, "The Snakeskin". And staying here, on his estate, one also learns of his three o'clock rite at his private cinema on Fårö. Lena Bergman, one of his daughters, describes "Ingmar welcomed people to share a movie experience with him in the way that others (normal people) invite their friends over for a meal. Dinners with Ingmar were rare, but sharing a film with him meant an invitation to get together. And often to talk - there were light-hearted and often lengthy post-cinema conversations in the sheltering gloom of the barn." In an era where film is often streamed and consumed in isolation on the sofa in contrast to being a social and communal act, Bergman's curiosity and film-watching ritual serve as encouragement for us to watch, talk, and think together about childhood and adolescence, as they are reflected in film. 
FURTHER READING AND VIEWING:

A Story of Children and Film - Mark Cousins

Watch Talk Think

Age of Innocence: Childhood on film, Pasquale Iannone Sight \& Sound Magazine April 2014 Issue.

British Film Institute. (2019). Licensing your community cinema | BFI Neighbourhood Cinema. Retrieved June 24, 2019, from

https://www.bfi.org.uk/neighbourhoodcinema/licensing-your-community-cinema

Images: My life in film, Ingmar Bergman. (1994) Bloomsbury publishing. ISBN-

13: 978-0747516705

The three o’clock rite: Ingmar Bergman's home cinema by Lena Bergman in Sight \& Sound.

Conflicts of Interest:

RB curates film events under the banner of "watch talk think" and receives no remuneration.

Funding/Acknowledgements: I am grateful to The Bergman Estate on Fårö for valuing the project and offering me a Residency to enable me to stop and think more deeply about the project. Many thanks to the other guests of the Estate for their stimulating conversation. I'm grateful to the V\&A Museum of Childhood, Foundling Museum, and all the panellists and audience members who have sustained the project into its sixth year.

Photographs:

Taken by Robindra BASU ROY June 2019 with permission of the Bergman Estate on Fårö.

1. Sculpture by Göran Wassberg (unclear name of piece or year), property of Bergman Estate on Fårö.

2. Ingmar Bergman's binoculars, property of Bergman Estate on Fårö. 